\title{
AIRWAY ASSESSMENT FOR ANTICIPATION OF DIFFICULT INTUBATION: A DOUBLE BLIND COMPARATIVE STUDY
}

\author{
Ushakumary Reghunathan'1, Radha Korumbil Raghavan², Bindu Mele Veetil ${ }^{3}$
}

${ }^{1}$ Additional Professor, Department of Anaesthesiology, Government Medical College, Kozhikode. ${ }^{2}$ Additional Professor, Department of Anaesthesiology, Government Medical College, Kozhikode. 3 Associate Professor, Department of Anaesthesiology, Government Medical College, Kozhikode.

\section{ABSTRACT}

\section{BACKGROUND AND AIMS}

In this era of high technology, we still face an ageless problem in anaesthesia - the difficult airway. In 1997, Smarajith Sur Roy of India introduced a new airway index to predict difficult intubation. Aim of the study is to compare the new airway index with modified Mallampati classification and also with Cormack and Lehane grading for predicting intubation difficulty.

\section{MATERIALS AND METHODS}

The study was conducted on 200 patients undergoing various surgeries at a Government Medical College Hospital. Patients between the age group of 15 to 50 years and belonging to American Society of Anaesthesiologist Grade 1 or 2 were selected. Patients were graded using Modified Mallampati classification. Then in hyperextended neck, the distance between the angle of mandible and the midpoint of Symphysis menti (Variable A) and the distance between the symphysis menti and the thyroid notch (Variable B) were taken in centimetres and A/B ratio calculated. This ratio is the New Airway Index. After premedication and induction of anaesthesia, laryngoscopy was done, Cormack and Lehane grade noted and intubation difficulty assessed. The predictive value of the new airway index was compared against modified Mallampati classification as well as Cormack and Lehane grading and statistical significance assessed.

\section{RESULTS}

The observations made on the calculation of the new airway index were, 1 . When the airway index was 1 , the intubation was very easy, irrespective of the findings of Mallampati classification and Cormack and Lehane Grade was $1 ; 2$. When the index was 1 to 1.399, the intubation was easier and the laryngoscopic findings were of Cormack and Lehane Grade II; 3. When the index was 1.4 or more, the intubation was difficult and they belonged to Cormack and Lehane Grade III. The predictability was also statistically very significant when compared with modified Mallampati classification $(\mathrm{p}<0.001$ - Chi square test - test for single proportion). The success rate of the new airway index was also high when compared with Cormack and Lehane grading.

\section{CONCLUSION}

This study confirms the efficacy of the new airway index in predicting difficult intubation.

\section{KEYWORDS}

Difficult Intubation, Prediction, Airway Assessment, New Airway Index.

HOW TO CITE THIS ARTICLE: Reghunathan U, Raghavan RK, Veetil BM. Airway assessment for anticipation of difficult intubation: a double blind comparative study. J. Evolution Med. Dent. Sci. 2016;5(40):2466-2469, DOI: 10.14260/jemds/2016/575

\section{INTRODUCTION}

In this era of high technology, we still face an ageless problem in anaesthesia - the difficult airway. Studies in UK, Australia and USA have shown that significant anaesthetic related mortality and morbidity are related to airway management.(15) The report of the Confidential Enquiry into Perioperative Deaths (CEPOD) published for England and Wales in 1986.(5) revealed that a difficult or failed intubation contributed to 6 of the 4034 deaths reported. Indeed as many as 600 deaths may occur each year as a result of difficult intubation.(6)

Simple tests, which may be able to identify those who are apparently normal but may prove difficult to intubate should be available. A number of bedside tests had been proposed.

Financial or Other, Competing Interest: None.

Submission 03-04-2016, Peer Review 30-04-2016,

Acceptance 05-05-2016, Published 19-05-2016.

Corresponding Author:

Dr. Ushakumary Reghunathan,

Harmony, D.P.O. Road,

Malappuram-676505,

Kerala,

India.

E-mail: surgeonuk@gmail.com

DOI: $10.14260 /$ jemds $/ 2016 / 575$
Patil et al(7) considered the Thyromental distance, Mallampati.(8) reported on a visual examination of the posterior wall of the pharynx and Frerk.(9) combined these tests to predict difficult intubation. Cormack and Lehane.(10) introduced grading according to the laryngoscopic visualization, which is the gold standard against which all bedside tests are compared. In 1997, Smarajith Sur Roy of India.(11) introduced a new airway index to predict difficult intubation.

\section{AIM OF THE STUDY}

To compare the new airway index proposed by Smarajith Sur Roy with modified Mallampati classification and also with Cormack and Lehane grading for predicting difficult intubation.

\section{MATERIALS AND METHODS}

The study was conducted as a double blind comparative study of the airway assessment using the new airway index with modified Mallampati classes and Cormack and Lehane grading. This study was conducted after obtaining institutional approval. The permission of the Ethical Committee of the hospital was also obtained. It was conducted on 200 patients undergoing various surgeries at a 
Government Medical College Hospital. Patients of both sex between the age group of 15 and 55 years and belonging to American Society of Anaesthesiologist Grade I or II were selected. Patients with obesity, malposition of teeth, microstomia, macroglossia, edentulous or with artificial dentures, cervical spondylosis, short neck, contractures of neck, neck swellings, post radiation fibrosis, developmental anomalies which may affect airway assessment and in whom difficult intubation was expected were excluded from the study.

Patient's age, sex, body weight, ASA grade, diagnosis and surgery were recorded. After initial clinical evaluation, they were graded using modified Mallampati grading. In hyperextended neck, the distance between the angle of mandible and the midpoint of symphysis menti (Variable A) and the distance between the symphysis menti and the thyroid notch (Variable B) were taken in centimetres (Fig. 1). Then the ratio A/B was taken and recorded.

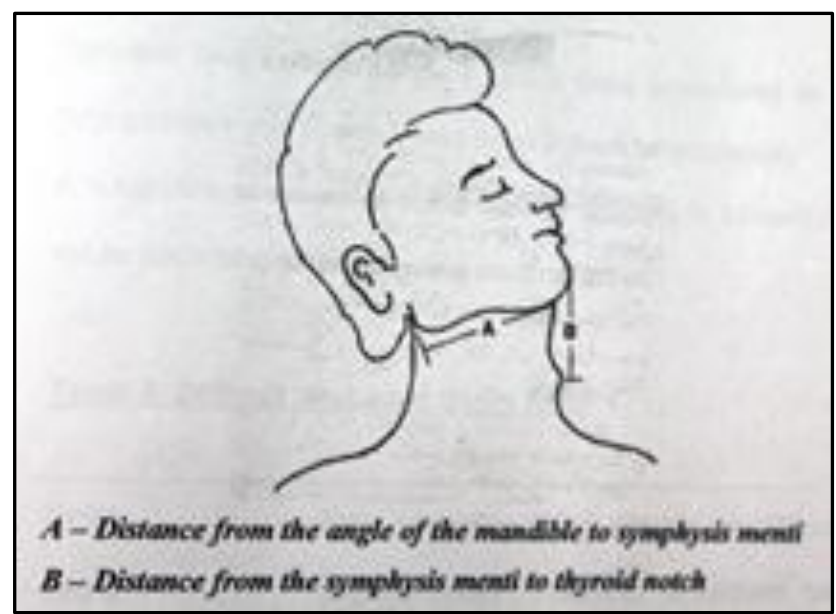

Fig. 1

A common anaesthesia protocol was followed in all patients, which included premedication with Inj. Pethidine 1 $\mathrm{mg} / \mathrm{kg}$ IM and Inj. Promethazine $0.5 \mathrm{mg} / \mathrm{kg} \mathrm{IM}$, standard monitoring with pulse oximetry, non-invasive blood pressure, end tidal $\mathrm{CO}_{2}$ and three-lead electrocardiogram. Adequate sniffing position was maintained by an $8 \mathrm{~cm}$ intubating pillow. After pre-oxygenation with $100 \%$ oxygen, the patients were induced with Inj. Thiopentone Sodium $5 \mathrm{mg} / \mathrm{kg}$ IV. After confirming adequacy of mask ventilation, Inj. Succinylcholine $2 \mathrm{mg} / \mathrm{kg}$ IV was given and were ventilated with 100\% oxygen through face mask. Laryngoscopic evaluation according to Cormack and Lehane grading was done by an Anaesthesiologist who was not aware of the modified Mallampati grading and the Variables A and B of the patient. The same person intubated the patient and ease of intubation was recorded. During laryngoscopy, the type of blade used and the need for pressure over the thyroid cartilage to visualize the larynx were also noted.

The ease of intubation on a subjective basis as easy, difficult or very difficult was recorded. Intubation difficulty was also scored on a seven-point scoring system (intubation difficulty score IDS) as devised by Adnet et al ${ }^{12}$ (Table 1).
It was made sure that the person who did the laryngoscopy and intubation had a minimum of three years of experience in clinical anaesthesiology.

\begin{tabular}{|c|c|}
\hline Variables & Score \\
\hline Number of attempts at intubation & $n-1$ \\
\hline Number of operators attempting intubation & $n-1$ \\
\hline Number of alternative techniques used & $n-1$ \\
\hline $\begin{array}{l}\text { Cormack and Lehane grade of laryngoscopy } \\
(1 / 2 / 3 / 4)\end{array}$ & $\begin{array}{c}\text { Grade - } \\
1\end{array}$ \\
\hline Increased lifting pressure required & 1 \\
\hline External pressure applied on larynx & 1 \\
\hline Mobile vocal cords & 1 \\
\hline \multicolumn{2}{|c|}{$\begin{array}{l}\text { Intubation Difficulty Score (IDS) = Sum of score of seven } \\
\text { variables; } \\
\text { IDS = } 0 \text { (Easy intubation) } \\
\text { IDS }=1-5 \text { (Moderately difficult intubation) } \\
\text { IDS }=5-15 \text { (Very difficult to impossible intubation) }\end{array}$} \\
\hline Table 1: Intubation Difficulty $S$ & \\
\hline
\end{tabular}

On completion of the study, the New Airway Index was compared with modified Mallampati classes in predicting difficult intubation. The new index was also compared with Cormack and Lehane grading and statistical significance was assessed.

\begin{tabular}{|c|c|}
\hline Age Group & No. of Patients \\
\hline $11-20$ & 41 \\
$21-30$ & 39 \\
$31-40$ & 53 \\
$41-50$ & 57 \\
$51-60$ & 10 \\
\hline TOTAL & $\mathbf{2 0 0}$ \\
\hline Mean Age & $\mathbf{3 5 . 1 3}$ \\
\hline
\end{tabular}

The New Airway Index was calculated as the ratio A/B; 188 patients belonged to the group of airway index less than 1.4 (Group A) and 12 were found in the group of airway index equal or more than 1.4 (Group B) (Table 3).

Among the 200 patients, 124 belonged to Mallampati class I, 71 to class II and 5 to class III. On comparing the New Airway Index with modified Mallampati classification (Table 3) it was found that of the 188 patients in the Group A, 124 were Mallampati Class I, 63 were Class II and only 1 was of Class III. Of the 12 patients in Group B, 8 were Mallampati Class II and 4 were Class III.

\begin{tabular}{|c|c|c|c|c|c|}
\hline & $\begin{array}{c}\text { Class } \\
\text { I }\end{array}$ & $\begin{array}{c}\text { Class } \\
\text { II }\end{array}$ & $\begin{array}{c}\text { Class } \\
\text { III }\end{array}$ & $\begin{array}{c}\text { Class } \\
\text { IV }\end{array}$ & Total \\
\hline $\begin{array}{c}\text { Airway } \\
\text { Index } \\
<1.4 \\
\text { (Group A) }\end{array}$ & 124 & 63 & 1 & 0 & 188 \\
\hline $\begin{array}{c}\text { Airway } \\
\text { Index } \\
\geq 1.4 \\
\text { (Group B) }\end{array}$ & 0 & 8 & 4 & 0 & 12 \\
\hline \multicolumn{5}{|c|}{ Table 3 } \\
\hline
\end{tabular}

On comparing with Cormack and Lehane grading, (Table 4) of the 188 patients in Group A, 103 were found to belong to Grade I and 85 to Grade II. Among the 12 patients in Group B, all were found to be Grade III. 


\begin{tabular}{|c|c|c|c|c|c|}
\hline & $\begin{array}{c}\text { Grade } \\
\text { I }\end{array}$ & $\begin{array}{c}\text { Grade } \\
\text { II }\end{array}$ & $\begin{array}{c}\text { Grade } \\
\text { III }\end{array}$ & $\begin{array}{c}\text { Grade } \\
\text { IV }\end{array}$ & Total \\
\hline $\begin{array}{c}\text { Airway } \\
\text { Index } \\
<1.4 \\
\text { (Group A) }\end{array}$ & 103 & 85 & 0 & 0 & 188 \\
\hline $\begin{array}{c}\text { Airway } \\
\text { Index } \\
\geq 1.4 \\
\text { (Group B) }\end{array}$ & 0 & 0 & 12 & 0 & 12 \\
\hline \multicolumn{5}{|c|}{ Table 4 } \\
\hline
\end{tabular}

The New Airway Index was calculated as the ratio A/B and it was found that when the ratio was less than 1.4 , the intubation was found easy and when the ratio was more than 1.4 the intubation was difficult.

Of the 200 patients all the 188 in Group A had no intubation difficulty, while all the 12 patients in Group B had intubation difficulty. One patient who was Mallampati Class III was found to have the new airway index less than 1.4 and Cormack and Lehane Class II and was easy to intubate. All the 12 patients in Group B were Cormack and Lehane Grade III and all had intubation difficulty, while only 4 had Mallampati grade III, predicting difficult intubation. So the predictive value of the New Airway Index was found to be better than the modified Mallampati.

The assessment was found correct in all the 200 cases and was also statistically very significant $(\mathrm{p}<0.001-$ Chi square test - test for single proportion) when compared with modified Mallampati classification. The success rate of the new airway index was also high when compared with Cormack and Lehane grading.

\section{DISCUSSION}

Airway compromise is the most common cause of death and morbidity in anaesthesia. Thus the primary responsibility of the anaesthesiologist is to preserve and protect the airway during all phases of anaesthesia. The first clinical step to the safe conduct of anaesthesia is airway evaluation. Difficult airway is defined as the clinical situation in which a conventionally trained anaesthesiologist experiences difficulty with mask ventilation or tracheal intubation or both. Difficult endotracheal intubation is defined as when an experienced laryngoscopist using direct laryngoscopy requires more than two attempts with the same blade or a change in the blade or use of an adjunct like bougie or use of an alternative device or technique following failed intubation with direct laryngoscopy.

Airway assessment includes general and regional assessment. Short and stumpy persons, women with large breasts, pregnant ladies, presence of ear and hand anomalies often suggest difficult intubation. Apart from anatomic causes for difficult intubation like short neck, micrognathia, prognathism and macroglossia, look for loose or missing teeth and dentures. Long incisors and involuntary overriding of the maxillary teeth make laryngoscopy difficult. The interincisor distance should be more than $3 \mathrm{~cm}$. Ability to protrude the mandibular teeth anterior to the maxillary teeth is a test for temporomandibular joint function, indicating good mouth opening and the ability to move the jaw anterior during laryngoscopy.
Thyromental distance less than $6 \mathrm{~cm}$, sternomental distance less than $12.5 \mathrm{~cm}$, hyomental distance less than two large finger breadths, anteriorly tilted larynx and reduction of atlanto-occipital joint extension suggest difficult intubation. Modified Mallampati grading, Wilson's score.(13) combined indicators by Frerk, Benumof.(14) and Butler PJ and Dhara SS.(15) are other clinical predictors of difficult intubation. Cormack and Lehane grading is a laryngoscopic assessment against which the accuracy of the rest are compared.

Smarajith Sur Roy proposed a new airway index, which is a very simple and highly predictable one as far as difficult intubation is concerned. This is a ratio of length of mandible to thyromental distance. For this, fixed bony landmarks like angle of mandible, symphysis menti and thyroid notch are used to take measurements. In this study, we compared the new airway index with Modified Mallampati in predicting difficult intubation and also verified with Cormack and Lehane grading. The observations made are, when the airway index (A/B ratio) was less than 1.4 the intubation was easy and Cormack and Lehane grade was 1 or 2; when the index was 1.4 or more, the intubation was difficult and Cormack and Lehane grades were 3 . Of the 12 patients in whom the index was 1.4 or more, 8 patients were Mallampati Class II predicting easy intubation which proved to be wrong. So the new airway index has better predictability compared to Modified Mallampati classification.

As per the developmental milestone of the mandible and the larynx, it is found that up to three years of age the growth and development of the mandible and the larynx may not keep pace with each other. So the new airway index is assessed from the age of five years onwards. It is noted that the size of the tongue (Reflected by the size of the body of the mandible) and the adequate room of the oral opening to the laryngeal inlet (Reflected by the thyromental distance) determine easy negotiation of the endotracheal tube. In patients with post-burn contracture of neck, the distance between the symphysis menti and the thyroid notch is reduced. In these patients, the new airway index will therefore be raised and intubation will be difficult.

But once the contracture is released this distance become normal and the ratio is reduced to near unity and the intubation becomes easy. This finding also proves the importance of the ratio $\mathrm{A} / \mathrm{B}$ in anticipating difficult intubation.

The simplified new airway index has better positive predictive value and higher sensitivity compared to modified Mallampati. The ideal pre-operative airway assessment should have high sensitivity and specificity and minimal false positive and false negative predictions. The new airway index comes close to the ideal one in terms of sensitivity and specificity.

\section{CONCLUSION}

This study confirms the efficacy of the New Airway Index proposed by Smarajith Sur Roy in predicting difficult intubation. This new airway index has almost $100 \%$ success rate in anticipating difficult intubation, so that one can be forewarned to be forearmed. This index has more predictive value than modified Mallampati classification. However, when an unexpected difficulty arises, flexible fibreoptic endoscopy may often provide a solution. 


\section{REFERENCES}

1. American society of anaesthesiologists, Committee on professional liability. Preliminary study of closed claims. ASA newsletter 1988;4(52):8-10.

2. Caplan RA, Ward RJ, Posner K, et al. Unexpected cardiac arrest during spinal anaesthesia: closed claims analysis of predisposing factors. Anaesthesiology 1988;68(1):511.

3. Caplan RA, Posner K, Ward RJ, et al. Adverse respiratory events in anaesthesia: a closed claim analysis. Anaesthesiology 1990;72(5):828-33.

4. Holland R. Anaesthesia related mortality in Australia. In:PierceEC, Cooper JB, eds. Instructional anaesthesia clinics. Boston: Little, Brown 1984:61-71.

5. Department of health and social security. Report on confidential enquiries into maternal deaths in England and Wales, 1979-1981. Report on health and social security subjects, 29. London:HMSO 1986.

6. King TA, Adams AP. Failed tracheal intubation. British Journal of Anaesthesia 1990;65:400-14.

7. Patil VU, Stehling LC, Zaunder HL. Fibreoptic endoscopy in anaesthesia. Chicago: Yearbook Medical 1983.

8. Mallampati SR, Gatt SP, Gugino LD, et al. A clinical sign to predict difficult tracheal intubation: a prospective study. Canadian Anaesthetists' Society Journal 1985;32(4):429-34.
9. Frerk CM. Predicting difficult intubation. Anaesthesia 1991;46(12):1005-8.

10. Cormack RS, Lehane J. Difficult tracheal intubation in obstetric anaesthesia 1984;39(11):1105-11.

11. Smarajith Sur Roy. New airway index to predict difficult intubation. Indian Journal of Anaesthesia 1997;41:1721.

12. Adnet F, Borron SW, Racine SX, et al. The intubation difficulty scale (IDS): proposal and evaluation of a new score characterizing the complexity of endotracheal intubation. Anaesthesiology 1997;87:1290-7.

13. Wilson ME, Spiegelhalter D, Robertson JA, et al. Predicting difficult intubation. British Journal of Anaesthesia 1988;61(2):211-16.

14. Benumof JL. Definition and incidence of difficult airway. In: Benumof JL, ed. Airway management principles and practice. St.Louis Mosby Ch.6, 1996;121-5.

15. Butler PJ, Dhara SS. Prediction of difficult laryngoscopy:an assessment of the thyromental distance and mallampati predictive tests. AnaesthIntens care1992;20(2):139-42. 